\title{
FIRST YEAR SCIENCE.
}

\section{BY HUdSON SHELDON, Lowell High School, San Francisco, California.}

The High School Section of the California Teachers' Association, at its December meeting in San Francisco, aroused considerable interest in the discussion of a general science course for high schools. The discussion was continued two days. Among those taking part were Dr. H. W. Fairbanks, Prof. Morgan, Mr. M. B. Nichols, Mr. E. W. Monroe, Miss Bridgeman, Mr. E. P. Carey, and Mr. A. L. Jordan. The discussion speedily resolved itself into an advocacy on the one hand of physical geography and on the other of an entirely new topic, general science, as the proper subject for first year instruction in science in the high school.

A committee to investigate present conditions in elementary science instruction in California high schools had issued a circular letter. Like all such letters, this appeal brought many answers of doubtful value. It appears that eighteen schools are now giving a course in general science and forty-seven are not, that twelve give no science to first year pupils, while thirty-one offer physical geography, and that a great increase in out-door work and observation is desirable. Forty-five teachers believe that there is need of a general science course, but, when the purpose and the content are discussed, it does not appear that the teachers in general have in mind a course differing greatly from physical geography as at present taught. The replies contained practically nothing that could indicate the content of a new course in general science.

The science teachers present followed the discussion with an abiding interest. The majority were in the attitude of inquirers, asking what general-science has to offer that physical geography does not give. The criticisms on physical geography seemed to be to the effect that teachers are not a unit in their understanding of the purpose of the science and the means the science should employ, and that the teaching is more or less desultory. To many of those present the advocates of general science did not seem able to offer anything to remedy these faults. In fact, the chief objection made to the general science course was that it lacks coherence and definiteness.

Two conclusions may fairly be drawn from the discussion. The first is that physical geography offers a good working basis for introduction to high school science. Mach has already been accomplished. This would be lost if the course were changed, and progress lies in the direction of more accurate definition of the course rather than in that of making the work more vague and general. The second conclusion is that the true field of a course in general science apart from physical geography is to prepare the way for high school science. Its place is in the seventh and eighth grades; but general science in the seventh and eighth grades, like all instruction in any grades, must be definite. The experiments must be directed to specific ends, and the organization must not be less precise than that of work in arithmetic or grammar.

Committees were appointed to consider the subject further and report in one year. 